\title{
A new high-performance liquid chromatographic method for the quality control of bioconverted Mori Folium extracts with appropriate marker compounds related to antidiabetes
}

\author{
Jin Hyeok Kim ${ }^{1 \dagger}$, Tae Jung Kim ${ }^{1 \dagger}$, Hyun June Kim, Chong Woon Cho ${ }^{1}$, Seok Jin Kim², Hyun So Cho², \\ Kyung Tae $\mathrm{Kim}^{3^{*}}$ and Jong Seong Kang ${ }^{*^{*}}$ (D)
}

\begin{abstract}
A HPLC method was developed to assess the enhanced bioactivity of bioconverted Mori Folium (MF) extract and to apply a quality-control system. Liquid-liquid extraction was applied to observe changes in chemical composition through enzymatic bioconversion. The ethyl acetate layer was used for quality control of the anti-diabetic functional MF product. A high-performance liquid chromatography method was developed to analyze five marker compounds (syringaldehyde, trans-caffeic acid, morin 3-O- $\beta$-D-glucopyranoside, astragalin, and moracin M 3'-O- $\beta$ glucopyranoside) within $60 \mathrm{~min}$. Optimized sample preparation was sonication for $44 \mathrm{~min}$ and a water-to-material ratio of $102.5 \mathrm{~mL} / \mathrm{g}$ by response surface methodology. Comparing MF water extract, trans-caffeic acid and syringaldehyde contents were increased 1.89 times and 2.70 times at Viscozyme-bioconverted material by applying the developed method. This HPLC method can be used to control the quality of bioconverted MF based on suitable bioactive markers and also applied to develop anti-diabetic functional foods containing Mori Folium.
\end{abstract}

Keywords: Mori Folium, HPLC, Bioconversion, Anti-diabetic activity, Quality control, Viscozyme

\section{Introduction}

Mulberry (Morus alba L.) leaves have been frequently used in medicinal herbal medicines and functional foods in Korea and China and are referred to by their Latin name of Mori folium (MF) (He et al. 2018). MF contains various bioactive compounds, including phenolic compounds, coumarins, terpenoids, melatonin, $\gamma$-aminobutyric acid, and alkaloids such as 1-deoxynojirimycin, deoxyuridine, and polysaccharides (Pothinuch et al. 2017; Yang and Han

\footnotetext{
*Correspondence: kimkkt@deu.ac.kr; kangjss@cnu.ac.kr

${ }^{\dagger}$ Jin Hyeok Kim and Tae Jung Kim contributed equally to this work.

${ }^{3}$ Department of Food Science and Technology, Dong-Eui University, Busan

47340, Korea

${ }^{1}$ College of Pharmacy, Chungnam National University, Daejeon 34134, South Korea

Full list of author information is available at the end of the article
}

2006). It has been reported that MF and its extracts have hypoglycemic effects and display antityrosinase, antidiabetic, and antioxidant activities (Yang et al. 2017). The various bioactive constituents in the root, fruit, and extracts of MF were recently reported to have antihyperlipidemic (Thirugnanasambandham et al. 2015), antidiabetic (Jha et al. 2013), antiobesity (Chang et al. 2016), neuroprotective (Seo et al. 2015), antimicrobial (Sohn et al. 2004), antiinflammatory (Eo et al. 2014), antitumor, and antiatherosclerotic activity (Cho et al. 2017; Huang et al. 2014).

Bioconversion, also referred to as biotransformation, is an interesting food and pharmaceutical processing method that can enhance the bioactivity of a material and its extracts (Anson et al. 2009). Microorganisms and enzymes are used in bioconversion processes. However, 
commercial enzymes (e.g., Viscozyme L. [EC 3.2.1.6]) are used in bioconversion processes in the food industry in preference to microorganisms because they have several advantages in terms of processing convenience, costefficiency with respect to equipment requirements, and a reduced need for government safety inspections (Guan and Yao 2008). In recent studies, $\beta$-glucosidase was used to improve the antioxidative activity of MF and its extracts (Ying et al. 2011). MF water extracts can be bioconverted by Viscozyme $\mathrm{L}$. and $\alpha$-glucosidase to improve antioxidative activity (Chen et al. 2015; Kim and Jang 2010). Bioactivity studies of MF have been conducted to assess the application of MF and its extracts to the treatment and prevention of diseases (Oku et al. 2006; Zhang et al. 2008). Numerous studies have attempted to develop a functional food using MF and MF extracts (Liu et al. 2009). Especially, our previous study proved enhanced antidiabetic activity of MF by bioconversion (Jung et al. 2019).

Many analytical studies of MF and its extracts have been conducted using high-performance liquid chromatography (HPLC) and liquid chromatography-mass spectrometry (LC-MS) (Zhang et al. 2008). The chemical composition of MF has been analyzed, and the major active compounds, such as rutin, quercetin, isoquercitrin, and other flavonoids, have been identified by HPLC and capillary electrophoresis (Tallini et al. 2015; Ying et al. 2011). MF polysaccharides have been analyzed by highpressure size exclusion chromatography and HPLC to determine their relationships with antidiabetic activity (Zhang et al. 2014). Pharmacokinetic studies of the antidiabetic properties of rutin and quercetin have been performed by reversed-phase HPLC and ultra-performance liquid chromatography coupled to electrospray ionization quadrupole time of fight mass spectrometry (Jha et al. 2013).

However, there is no consensus analytical method and marker compound for quality control of enzymebioconverted MF to apply antidiabetes. Therefore, this study aimed to develop an analytical method using HPLC for quality control of the bioconverted MF extract, and to determine key compounds related to the improved antidiabetic activity compared to the MF water extract.

\section{Materials and methods Chemicals and samples}

Syringaldehyde and trans-caffeic acid were purchased from Sigma-Aldrich (St. Louis, MO, USA). Other standard compounds (morin 3-O- $\beta-D-$ glucopyranoside, moracin $M$ 3'-O- $\beta$-glucopyranoside, and astragalin) were provided by Professor Young Ho Kim of the College of Pharmacy, Chungnam National University (Daejeon, South Korea). All standards had a purity higher than
95\%, and their chemical structures are shown in Fig. 1. Methanol, ethyl acetate (EtOAc), and acetonitrile (HPLC grade) were purchased from Honeywell Burdick \& Jackson (Muskegon, MI, USA). Formic acid (HPLC grade) was purchased from Sigma-Aldrich. The other chemicals used guaranteed reagent (GR) grade. Ultrapure water was manufactured by a Milli-Q water purification system (Shinhan, Daejeon, South Korea).

\section{Analytical sample preparation}

Sample preparation was modified from Zhang et al. (2008). All samples were dried, finely ground in a food mixer (HMF-3080SS; Hanil, Seoul, Korea), and passed through a 20 mesh sieve. A $0.2 \mathrm{~g}$ sample of the resulting powder was extracted with different volumes of various solvents by sonication $(35 \mathrm{kHz}, 118.5 \mathrm{~W})$ using an ultrasonicator (SD-D250H, Sungdong, Seoul, Korea). In the extraction process, sonication was used to ensure an efficient extraction from MF (Vichasilp et al. 2009; Ying et al. 2011). The sample extraction conditions were optimized by response surface methodology (RSM). The water extract was centrifuged at $3500 \mathrm{rpm}$ for $5 \mathrm{~min}$ using a centrifuge (Smart R17; Hanil, Daejeon, Korea). The separated supernatant was combined with $20 \mathrm{~mL}$ of EtOAc for liquid-liquid extraction (LLE). The LLE process was repeated twice. All EtOAc layers were collected and evaporated at $40^{\circ} \mathrm{C}$, and then, $2 \mathrm{~mL}$ of methanol was added to dissolve the residue. This solution passed through a $0.22-\mu \mathrm{m}$ syringe filter, and $10 \mu \mathrm{L}$ was used in the HPLC analysis.

\section{Standard preparation and the calibration curve}

The standard stock solutions of trans-caffeic acid ( $1 \mathrm{mg} /$ $\mathrm{mL})$, syringaldehyde $(1 \mathrm{mg} / \mathrm{mL})$, morin $3-\mathrm{O}-\beta-\mathrm{D}$-glucopyranoside $(1 \mathrm{mg} / \mathrm{mL})$, moracin $\mathrm{M} 3$ '-O- $\beta$-glucopyranoside $(0.1 \mathrm{mg} / \mathrm{mL})$, and astragalin $(0.15 \mathrm{mg} / \mathrm{mL})$ were prepared individually using methanol and kept at $4{ }^{\circ} \mathrm{C}$ prior to use. For the calibration curve, five different concentrations of each compound were used as follows: 1.3, $12.5,25.0,50.0$, and $100.0 \mu \mathrm{g} / \mathrm{mL}$ for trans-caffeic acid, syringaldehyde, and morin 3-O- $\beta$-D-glucopyranoside; $0.1,1.3,2.5,5.0$, and $10.0 \mu \mathrm{g} / \mathrm{mL}$ for moracin M $3^{\prime}-\mathrm{O}-\beta$ glucopyranoside; and 1.8, 3.6, 7.3, 14.5 , and $29.0 \mu \mathrm{g} / \mathrm{mL}$ for astragalin. All standard solutions were passed through a $0.22-\mu \mathrm{m}$ syringe filter before analysis by HPLC.

\section{HPLC analytical method}

The HPLC instrument was a Shimadzu LC-20A HPLC system (Shimadzu, Kyoto, Japan) equipped with a CBM20A communication bus module, SPD-20A UV-visible detector, LC-20 AD pump, SIL-20A auto sampler, and CTO-20A column oven. The HPLC analysis was performed on an Optimapak C18 column $(250 \times 4.6 \mathrm{~mm}$, 
<smiles>COc1cc(C=O)cc(OC)c1O</smiles>

(c)

(a)<smiles>OC[C@H]1O[C@@H](Oc2cc(O)cc(-c3cc4ccc(O)cc4o3)c2)[C@H](O)[C@@H]1O</smiles>

(d)<smiles>O=c1c(O[C@@H]2O[C@H](CO)[C@@H](O)[C@H](O)[C@H]2O)c(-c2ccc(O)cc2O)oc2cc(O)cc(O)c12</smiles>

(e)

Fig. 1 Chemical structures of five major compounds in MF water extract and bioconverted MF: a trans-caffeic acid, $\mathbf{b}$ syringaldehyde, c morin 3O- $\beta$-D-glucopyranoside, $\mathbf{d}$ moracin M 3'-O- $\beta$-glucopyranoside, and e astragalin

$5 \mu \mathrm{m}$; RStech Corp., Daejeon, Korea) with a mobile phase of $0.1 \%$ formic acid in water (A) and $0.1 \%$ formic acid in acetonitrile (B) under the following gradient conditions: $5 \sim 20 \% \mathrm{~B}$ at $0 \sim 120 \mathrm{~min}$ and $20 \sim 61 \% \mathrm{~B}$ at $120 \sim 145 \mathrm{~min}$. An UV detection wavelength of $320 \mathrm{~nm}$, column temperature of $25^{\circ} \mathrm{C}$, and flow rate of $0.7 \mathrm{~mL} /$ min were used. The injection volume of standards and samples was $10 \mu \mathrm{L}$.

\section{Analysis by HPLC coupled with diode array detection (DAD), electrospray ionization (ESI) and tandem MS (HPLC-DAD-ESI-MS/MS)}

Identification of the major compounds in MF was performed by an LCMS-8040 system (Shimadzu) equipped with a CBM-20A communication bus module, SPDM20A photodiode array detector, LC-20 AD pump, SIL20A auto sampler, CTO-20A column oven, and an ESI source in positive and negative mode. The HPLC-DAD analysis of the main compounds was conducted in an Optimapak $\mathrm{C}_{18}$ column $(250 \times 4.6 \mathrm{~mm}, 5 \mu \mathrm{m}$; RStech Corp.), with a mobile phase of $0.1 \%$ formic acid in water (A) and $0.1 \%$ formic acid in acetonitrile (B) under the same conditions as in the HPLC analysis. The main compounds within the MF were monitored in the range of UV 190 400 nm (split, $1.2 \mathrm{~nm}$ ). The LC-MS analysis was performed at an interface voltage of $4.5 \mathrm{kV}$, and the ESI interface was $-3.0 \mathrm{kV}$. The other conditions were a drying gas flow of $15 \mathrm{~L} / \mathrm{min}$, nebulizing gas flow of $3 \mathrm{~L} /$ min, desolation line temperature of $250{ }^{\circ} \mathrm{C}$, and heat block temperature of $400^{\circ} \mathrm{C}$ at a flow rate of $0.7 \mathrm{~mL} /$ min.

\section{Method validation}

The chromatographic method was validated in terms of specificity, linearity, intra-/inter-day precision and accuracy, and recovery. The specificity of each peak in the sample was examined by comparing UV spectra at three points per peak. Linearity was verified by the determination coefficient $\left(r^{2}\right)$ of the calibration curve between the peak area and the standard concentration. The limits of detection (LODs) and limits of quantification (LOQs) of each component were calculated as 3.3 and 10 times the signal-to-noise $(S / N)$, respectively. The precision and accuracy of each compound were assessed in triplicate at three different concentrations (low, middle, and high), over the range of the calibration curve five times a day for the intra-day assessment, and over 5 continuous days for the inter-day assessment. Recovery was determined in triplicate by spiking three concentrations $(80 \%, 100 \%$, and $120 \%$ ) of each compound and applying the following 
equation: recovery $(\%)=(\mathrm{a}$ "found" concentration $) /(\mathrm{a}$ theoretical concentration) $\times 100 \%$.

\section{Optimization of analytical sample preparation conditions} For analytical sample preparation, extraction solvents (water, 50\% methanol, and 100\% methanol), sonication time (15 60 $\mathrm{min})$, and the solvent-to-material ratio (50, 75,100 , and $125 \mathrm{~mL} / \mathrm{g}$ ) were verified. The sample preparation conditions for bioconverted MF were optimized by the RSM based on a central composite design (CCD) using the sonication time and solvent-to-material ratio. The experiment was designed, and statistical analyses performed, using a trial version (ver. 10.0) of the DesignExpert software (Stat-Ease Inc., Minneapolis, MN, USA). The optimized conditions were identified for sample preparation by comparing the value predicted by RSM and the experimental result.

Finally, the total experimental procedure is illustrated in Fig. 2 for better understanding.

\section{Results and discussion}

Selection of marker compounds by pattern analysis

The bioconverted MF extracts were compared to MF water extracts for the selection of marker compounds as a quality-control measure. When an MF water extract was compared to a bioconverted MF extract, it was difficult to determine if changes in the MF chromatogram pattern were due to bioconversion or matrix effects. The HPLC patterns of the two extracts were very similar without LLE (Supplementary Figure 1). From previous studies, it was considered that the fatty acids and carbohydrates in MF could have affected the analysis. The dried MF had a carbohydrate content of 9.70 to $39.70 \%$ and a fatty acid content of 2.09 to $6.90 \%$, values which can increase viscosity, thus causing compounds to agglomerate (Ustundag and Ozdogan 2015). Fatty acids and carbohydrates can reduce the separation efficiency and compound selectivity by decreasing the interactions between a compound and the stationary phase (Le et al. 2017). Thus, LLE was applied for sample extraction to improve the detection of major compounds, and EtOAc was used according to Zhang et al. (2008). After the LLE process was applied to $\mathrm{MF}$, an intense increase in each peak of the main components of the bioconverted MF extracts on the chromatogram was clearly observed in the EtOAc layer (Fig. 3).

In the resulting HPLC pattern analysis, eight peaks (compounds 1-8) were increased or decreased by the bioconversion of MF extracts. Considering the detection sensitivity, five peaks (compounds 1-5) among the marker compounds were selected.

\section{Identification of five compounds by LC-MS/MS}

The UV and MS spectrums of five selected compounds (compounds 1-5) were compared using standards specific for each compound. The maximum absorption wavelength $\left(\lambda_{\max }\right)$ of each compound was as follows: UV 217, 234, and $323 \mathrm{~nm}$ for compound 1; UV 209, 226, and $309 \mathrm{~nm}$ for compound 2; UV 201, 255, and $354 \mathrm{~nm}$ for compound 3; UV $315 \mathrm{~nm}$ for compound 4; and UV 214, 264, and $341 \mathrm{~nm}$ for compound 5 . The best UV wavelength for the detection of the five components (compounds 1-5) was UV $320 \mathrm{~nm}$, considering the UV $\lambda_{\max }$ of each compound. The precursor ions of compounds 1-5 were assigned by LC-MS analysis, as follows: $[\mathrm{M}-\mathrm{H}]^{-}, m / z=178.95$ for compound $1 ;[\mathrm{M}+$ $\mathrm{H}]^{+}, m / z=183.05$ for compound $2 ;[\mathrm{M}+\mathrm{H}]^{+}, m / z=$ 465.05 for compound 3 ; $[\mathrm{M}-\mathrm{H}]^{-}, \mathrm{m} / z=449.15$ for compound 4 ; and $[\mathrm{M}+\mathrm{H}]^{+}, m / z=449.10$ for compound 5 .

The five selected candidate markers were identified by HPLC-DAD-ESI-MS/MS according to retention time, UV-spectrum, molecular weight, and MS/MS fragment ion data in comparison to each standard. The five selected compounds were identified as trans-caffeic acid, syringaldehyde, morin $3-\mathrm{O}-\beta-\mathrm{D}$-glucopyranoside, moracin $\mathrm{M}-3^{\prime}$-O- $\beta$-glucopyranoside, and astragalin (Table 1 ).

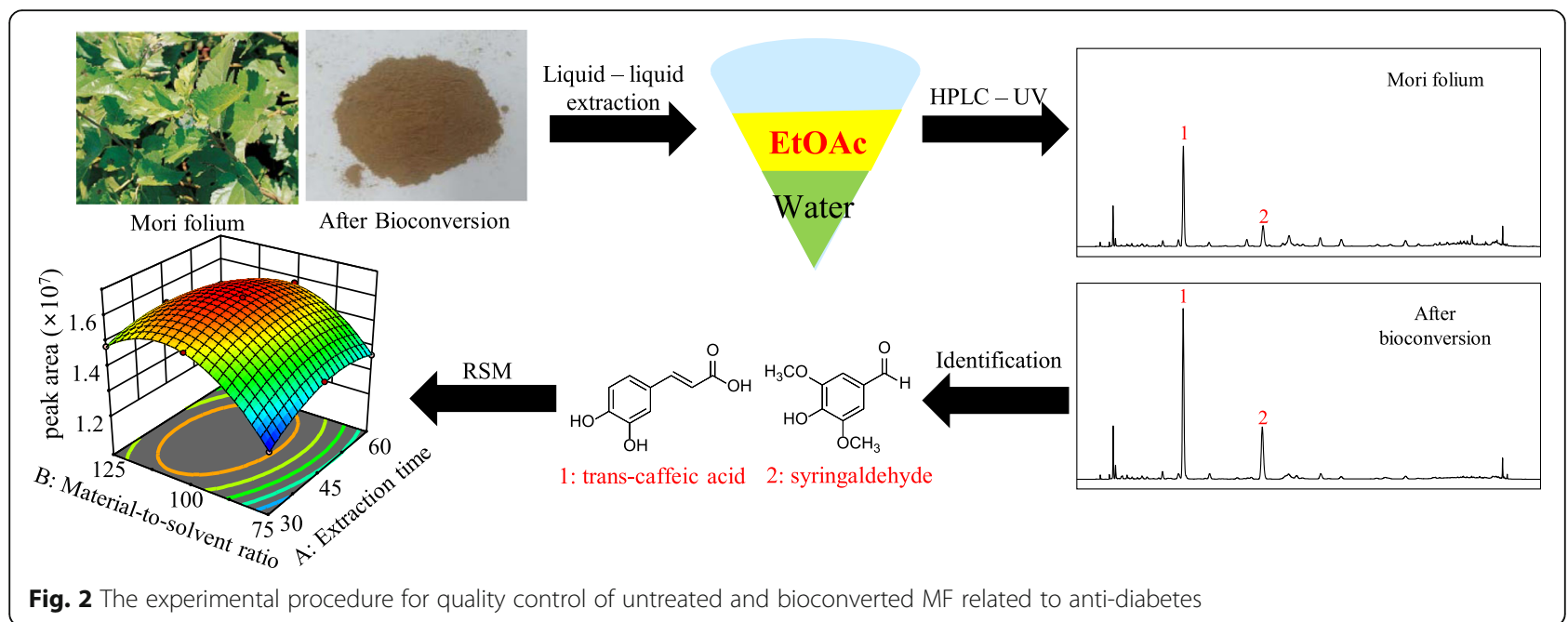

Fig. 2 The experimental procedure for quality control of untreated and bioconverted MF related to anti-diabetes 


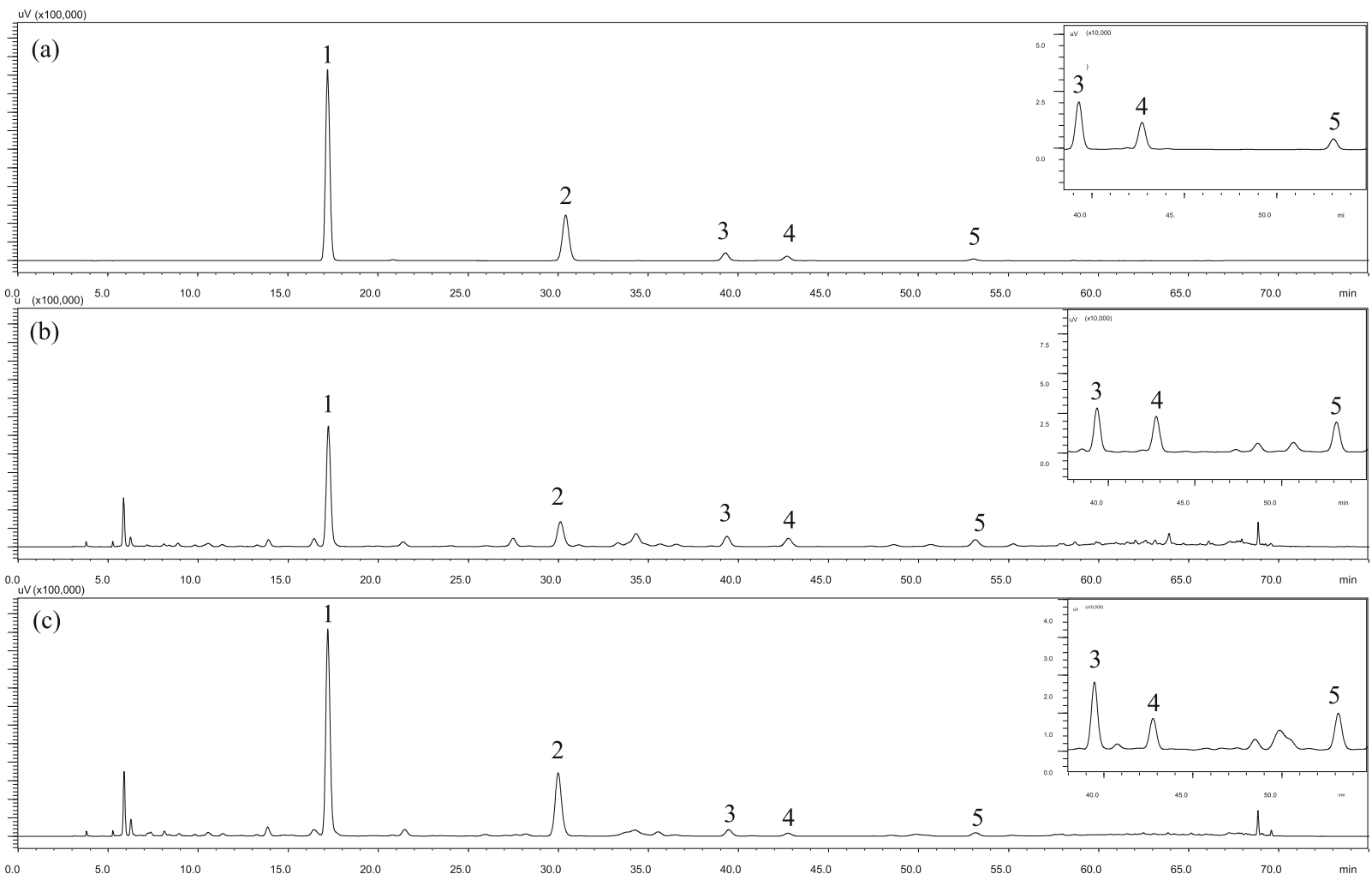

Fig. 3 HPLC chromatograms of a standard mixture, b MF water extract, and c bioconverted MF; 1, trans-caffeic acid; 2, syringaldehyde; 3, morin 3-O- $\beta$-D-glucopyranoside; 4, moracin M 3'-O- $\beta$-glucopyranoside; and 5, astragalin

Marker candidates were detected in both water extract and bioconverted MF. The bioactivities of selected marker candidates were verified to confirm the marker compounds and explain the enhanced bioavailability of bioconverted MF extract. Syringaldehyde $(0.73 \mu \mathrm{g} / \mathrm{g})$ is an antidiabetic compound (Huang et al. 2012). Trans-caffeic acid $(0.58 \mu \mathrm{g} / \mathrm{g})$ is a secondary abundant ingredient in bioconverted MF extract, and its known bioactivities are growth-stimulatory, antitumor, and antidiabetic activities (Dhungyal et al. 2014; Tyszka et al. 2017; Vendrig and Buffel 1961). Morin 3-O- $\beta$-D-glucopyranoside has anti- cancer, allelopathic, antifungal, and antioxidant activities (Jin et al. 2014). Moracin M 3'-O- $\beta$-glucopyranoside has moderate tyrosinase inhibitory activities (Kang et al. 2011). Astragalin, an antioxidant, is a representative compound of Morus alba leaves (Choi et al. 2013). In consideration of their peak detection sensitivity and antidiabetic activity, syringaldehyde and trans-caffeic acid were suggested as marker compounds for the quality control of bioconverted MF extract when applying a commercial antidiabetic extract.

Table 1 Peak identification of five marker candidates in bioconverted MF extract by HPLC-DAD-ESI-MS/MS

\begin{tabular}{|c|c|c|c|c|c|c|c|c|}
\hline Compound No. & $\begin{array}{l}\text { Retention } \\
\text { time (min) }\end{array}$ & UV $\lambda(n m)$ & $\begin{array}{l}\text { Molecular } \\
\text { weight }\end{array}$ & $\begin{array}{l}\text { Molecular } \\
\text { formula }\end{array}$ & $\mathrm{MS}^{1}(\mathrm{~m} / \mathrm{z})$ & MS $^{2}$ (Rel. Int. \%) & Identification & CE (V) \\
\hline 1 & 17.67 & 217,323 & 180 & $\mathrm{C}_{9} \mathrm{H}_{8} \mathrm{O}_{4}$ & {$[\mathrm{M}-\mathrm{H}]^{-}(178.95)$} & $134.80(100 \%), 133.90(15 \%)$ & Trans-caffeic acid & 17.0 \\
\hline 2 & 30.51 & 217,309 & 182 & $\mathrm{C}_{7} \mathrm{H}_{6} \mathrm{O}_{4}$ & {$[\mathrm{M}+\mathrm{H}]^{+}(183.05)$} & $\begin{array}{l}155.15(38 \%), 123.10(100 \%), \\
95.05(71 \%), 77.00(84 \%), \\
65.10(23 \%)\end{array}$ & Syringaldehyde & -12.0 \\
\hline 3 & 41.24 & $212,253,351$ & 464 & $\mathrm{C}_{21} \mathrm{H}_{20} \mathrm{O}_{12}$ & {$[\mathrm{M}+\mathrm{H}]^{+}(465.05)$} & $303.00(100 \%)$ & $\begin{array}{l}\text { Morin-O- } \beta \text {-D- } \\
\text { glucopyranoside }\end{array}$ & -12.0 \\
\hline 4 & 44.27 & 219,316 & 404 & $\mathrm{C}_{20} \mathrm{H}_{20} \mathrm{O}_{9}$ & {$\left[\mathrm{M}+\mathrm{HCOO}^{-}(449.15)\right.$} & 403.05 (50\%), 240.90 (100\%) & $\begin{array}{l}\text { Moracin M-3'-O- } \beta \text { - } \\
\text { glucopyranoside }\end{array}$ & 20.0 \\
\hline 5 & 53.57 & $214,265,339$ & 448 & $\mathrm{C}_{21} \mathrm{H}_{20} \mathrm{O}_{11}$ & {$[\mathrm{M}+\mathrm{H}]^{+}(449.10)$} & $\begin{array}{l}284.90(29 \%), 283.95(100 \%), \\
254.90(70 \%), 226.95(69 \%)\end{array}$ & Astragalin & -13.0 \\
\hline
\end{tabular}




\section{Optimization of the analytical method}

After selecting the marker compounds, the HPLC method was optimized to increase analytical efficiency by improving the shape of the selected peaks and analytical time. First, the effect of including an acidic modifier in the mobile phase was verified for the selected peaks using $0.1 \%$ formic acid. Peak tailing was reduced, and the symmetry of the peak improved, by adding the acidic modifier; $0.1 \%$ formic acid was added to both mobile solvents (Supplementary Figure 2). Many small peaks appeared and disappeared by adding $0.1 \%$ formic acid. In details, the peak at $61 \mathrm{~min}$ disappeared, and the highest peak at 53 min newly found by adding $0.1 \%$ formic acid. The gradient condition of the mobile phase was then adjusted to reduce the total analytical time, with consideration of peak separation for the five marker compounds (Supplementary Figure 3 ). The best gradient condition was 15 to $20 \mathrm{~B} \%$ at $0-45 \mathrm{~min}$ and 20 to $45 \mathrm{~B}$ $\%$ at $45-60 \mathrm{~min}$. Total analytical time was reduced to 60 min when pattern analysis was used for optimization.

\section{Optimization of sample preparation by RSM}

In the pattern analysis, it was difficult to determine the compounds that were changed in the bioconverted MF extract compared to the MF water extract in the HPLC pattern analysis. This was likely due to the matrix effects in the results arising from the more complicated composition of the MF following bioconversion. Therefore, LLE was essentially used to verify the improvement in bioactive compounds, and for quality control of the bioconverted MF extract.

Using the information obtained from the HPLC pattern analysis, analytical sample preparation was improved by optimizing the extraction solvent, extraction process, extraction time, and solvent-material ratio. The key factors in sample preparation are the extraction time and solvent-material ratio, which were optimized by RSM.

Water was used as the extraction solvent because its extraction efficiency for the five marker compounds was higher than that of the other solvents (Supplementary Figure 4). Thirteen RSM runs were performed to obtain the response values for three levels of a CCD (Table 2). The dependent variable was the peak area $(\mathrm{Y})$ of the five main compounds determined by quantitative HPLCDAD-ESI-MS-MS. The optimal conditions for analytical sample preparation were predicted to be an extraction time of $44.25 \mathrm{~min}$ and a solvent-to-material ratio of $102.50 \mathrm{~mL} / \mathrm{mg}$ (Fig. 4). The suitability of the RSM was confirmed by a fitness and $p$ value as 2482.23 and 0.001 , respectively (Supplementary Table 1). To apply these conditions in actual experiments, the predicted values were modified slightly to $44 \mathrm{~min}$ and $105 \mathrm{~mL} / \mathrm{mg}$, respectively. When an actual experiment was performed
Table 2 The central composite design matrix for optimal sample preparation

\begin{tabular}{|c|c|c|c|}
\hline \multirow[t]{2}{*}{ Run } & \multicolumn{2}{|c|}{ Independent variables } & \multirow{2}{*}{$\begin{array}{l}\text { Peak area } \\
Y\left(* 10^{6}\right)\end{array}$} \\
\hline & $\begin{array}{l}X_{1} \text { extraction } \\
\text { time }(\min )\end{array}$ & $\begin{array}{l}\mathrm{X}_{2} \text { solvent-to-material } \\
\text { ratio }(\mathrm{mL} / \mathrm{g})\end{array}$ & \\
\hline 1 & $45(0)$ & $100(0)$ & 16.3 \\
\hline 2 & $45(0)$ & $100(0)$ & 16.4 \\
\hline 3 & $45(0)$ & $100(0)$ & 16.3 \\
\hline 4 & $45(0)$ & $100(0)$ & 16.3 \\
\hline 5 & $30(-1)$ & $100(0)$ & 15.5 \\
\hline 6 & $60(1)$ & $125(1)$ & 14.4 \\
\hline 7 & $30(-1)$ & $75(-1)$ & 12.8 \\
\hline 8 & $45(0)$ & $75(-1)$ & 14.0 \\
\hline 9 & $60(1)$ & $75(-1)$ & 13.7 \\
\hline 10 & $45(0)$ & $100(0)$ & 16.3 \\
\hline 11 & $60(1)$ & $100(0)$ & 15.8 \\
\hline 12 & $45(0)$ & $125(1)$ & 14.8 \\
\hline 13 & $45(0)$ & $125(1)$ & 15.3 \\
\hline
\end{tabular}

using the modified values of the RSM model, the experimental result showed a $98 \%$ match to that predicted by the model (Supplementary Table 2). This indicates that the optimal conditions obtained in this study can be applied to the analytical sample preparation process, for quality control and manufacture of a bioconverted MF extract with antidiabetic properties. In summary, the optimized sample preparation process for bioconverted MF extract is as follows: A $0.2 \mathrm{~g}$ sample of the powder is extracted with $20.5 \mathrm{~mL}$ of water in a conical flask by sonication for $44 \mathrm{~min}$ and then centrifuged (3500 rpm for 5 min). The supernatant from this mixture is mixed with the same value of EtOAc for LLE, which is repeated three times. All EtOAc partitions are merged and evaporated and then methanol $(2 \mathrm{~mL})$ is added to dissolve the residue. The final solution is filtered through a $0.22-\mu \mathrm{m}$ syringe filter and used as the analytical sample.

\section{Method validation}

When the UV spectra of three points on each peak in the sample were compared, all spectra of the peak were exactly matched. It indicated that the separated peaks had sufficient specificity, with no contamination by other components (Supplementary Figure 5). The coefficient of determination for linearities $\left(R^{2}\right)$ of the five marker compounds were greater than 0.9994; therefore, it was confirmed that the peak area increased in relation to the analyte concentration over the selected concentration range. The LOD and LOQ of the marker compounds were $0.010 \sim 0.135$ and $0.029 \sim 0.411 \mu \mathrm{g} / \mathrm{mL}$, respectively (Supplementary Table 3). The precision and accuracy for marker compounds determined by intra- and inter- 


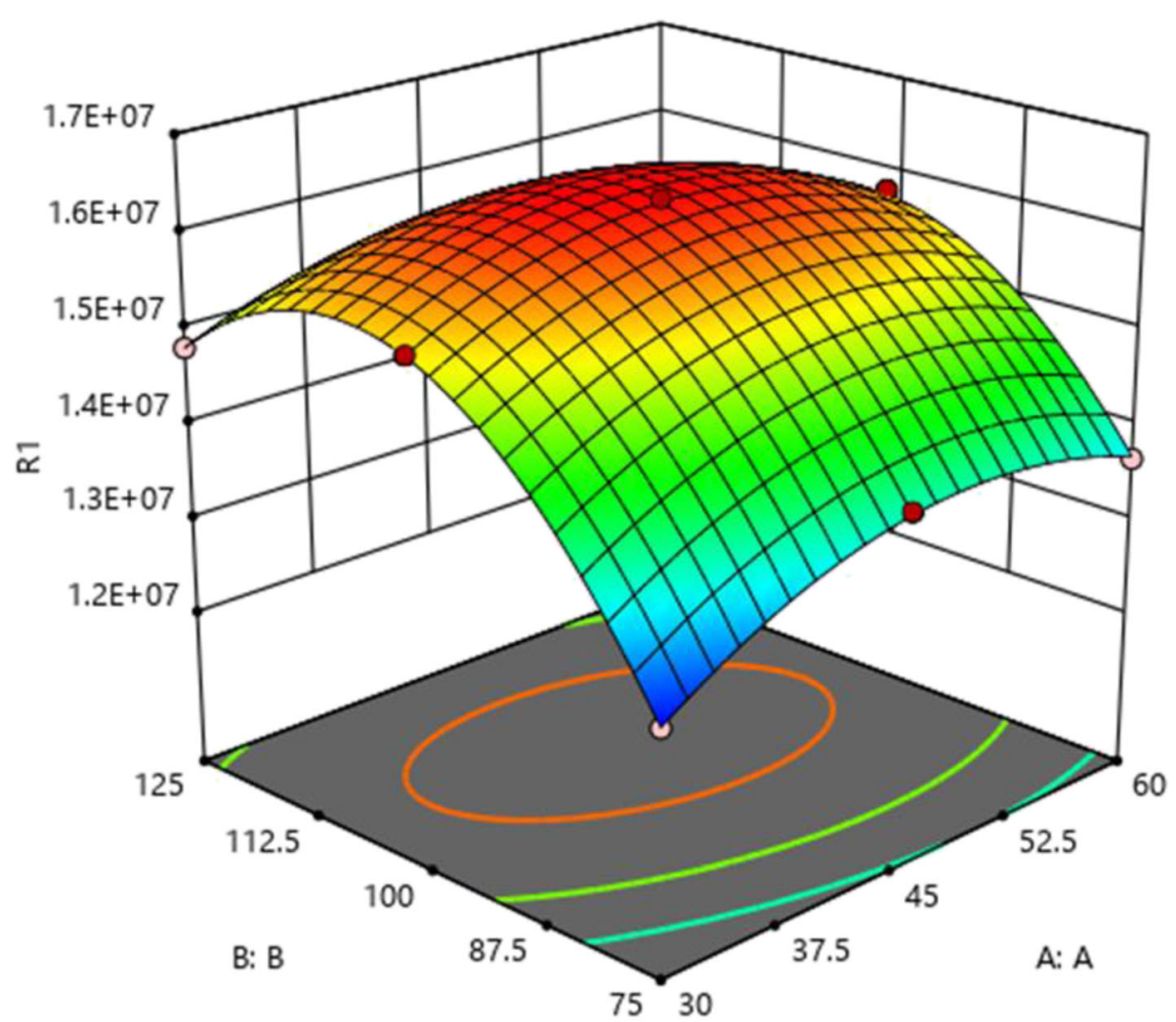

A: extraction time

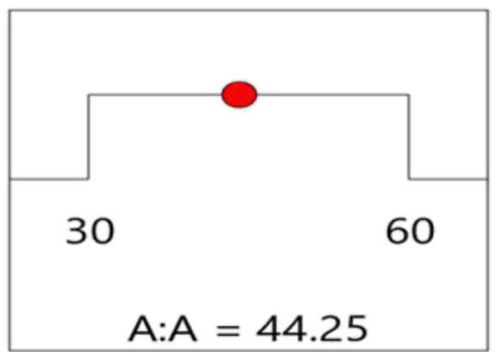

B: water-to- material ratio

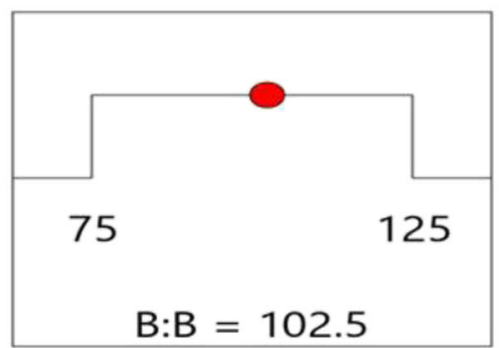

Fig. 4 Optimal extraction conditions of five major compounds for bioconverted MF extract by RSM

day analysis were below $2.0 \%$ RSD and 98.6 to $103.8 \%$, respectively (Supplementary Table 4).

The repeatability of the developed method was good, with RSD values less than $1.30 \%$. The quantitation and relative retention time results are given in Supplementary Table 5. When each standard was spiked in the bioconverted MF sample, the recovery of the marker compounds ranged from 97.97 to $103.56 \%$, with an RSD less than 3\% (Supplementary Table 6). Considering the repeatability and recovery results, it was confirmed that the analytical method developed in this study had sufficient reproducibility. The validation data indicated the appropriateness of the developed method with regard to the method validation guidelines of the Ministry of Food and Drug Safety, South Korea (KFDA), US Food and
Drug Administration (FDA), and International Council for Harmonisation (ICH).

\section{Content of major compounds}

The MF extract was bioconverted by Viscozyme to enhance its antidiabetic function. However, quantitative variation in the bioconverted MF was not readily easily observed, and quality control was difficult. Therefore, LLE was applied, and the EA fraction was used for quality control of the bioconverted MF extract. Based on the quantitative analysis data for the five marker compounds, their concentrations in the bioconverted MF extract followed the order of syringaldehyde $(0.73 \mu \mathrm{g} / \mathrm{g})>$ trans-caffeic acid $(0.58 \mu \mathrm{g} / \mathrm{g})>$ morin 3-O- $\beta$-D-glucopyranoside $(0.48 \mu \mathrm{g} / \mathrm{g})>$ astragalin $(0.17 \mu \mathrm{g} / \mathrm{g})>\operatorname{moracin} \mathrm{M}$ 
Table 3 Quantitative analysis of five marker compounds in MF water extract and bioconverted MF extract $(n=6)$

\begin{tabular}{|c|c|c|c|c|c|}
\hline \multirow{2}{*}{$\begin{array}{l}\text { Compound } \\
\text { No. }\end{array}$} & \multicolumn{2}{|c|}{ MF water extract } & \multicolumn{2}{|c|}{ Bioconverted MF } & \multirow{2}{*}{$\begin{array}{l}\text { Bioconverted } \\
\text { MF/MF water } \\
\text { extract }\end{array}$} \\
\hline & Conc. $(\mu \mathrm{g} / \mathrm{g})^{\mathrm{a}}$ & RSD (\%) & Conc. $(\mu \mathrm{g} / \mathrm{g})^{\mathrm{a}}$ & RSD (\%) & \\
\hline 1 & $0.39 \pm 0.02$ & 1.15 & $0.73 \pm 0.01$ & 1.69 & 1.89 \\
\hline 2 & $0.21 \pm 0.01$ & 1.43 & $0.58 \pm 0.02$ & 2.83 & 2.70 \\
\hline 3 & $0.55 \pm 0.01$ & 2.09 & $0.47 \pm 0.01$ & 1.86 & 0.88 \\
\hline 4 & $0.29 \pm 0.01$ & 1.04 & $0.17 \pm 0.01$ & 2.14 & 0.58 \\
\hline 5 & $0.10 \pm 0.01$ & 1.23 & $0.05 \pm 0.01$ & 2.08 & 0.52 \\
\hline
\end{tabular}

${ }^{\mathrm{a}}$ Data are represented as mean $\pm \mathrm{SD}$

3'-O- $\beta$-glucopyranoside $(0.05 \mu \mathrm{g} / \mathrm{g})$. In comparison to the MF water extract, trans-caffeic acid and syringaldehyde were increased by 1.89 and 2.7 times, respectively, in the bioconverted MF extract. In contrast, morin 3-O$\beta$-D-glucopyranoside, moracin M 3'-O- $\beta$-glucopyranoside, and astragalin were decreased by $0.88,0.58$, and 0.52 times, respectively (Table 3 ). These results support our previous experiment that bioconverted MF showed better antidiabetic action than unaltered MF in mice (Jung et al. 2019). Thus, the key compounds of enhanced antidiabetic effect were considered syringaldehyde and trans-caffeic acid, and they should be used for maker compounds for quality control.

Based on the quantitative monitoring data, the average concentrations of syringaldehyde and trans-caffeic acid were $0.73 \pm 0.01$ and $0.58 \pm 0.02 \mu \mathrm{g} / \mathrm{g}$, respectively, and their RSDs were 1.69 and $2.83 \%$, respectively. Therefore, the criteria used to determine the commercial suitability of bioconverted MF for treating diabetes was suggested to be a syringaldehyde concentration of $0.58 \mu \mathrm{g} / \mathrm{g}$ and trans-caffeic acid concentration of $0.46 \mu \mathrm{g} / \mathrm{g}$ in $80.0 \%$, based on all of the data for each marker.

\section{Conclusion}

The purpose of this study was to determine the key active compounds that explain why a bioconverted MF extract has enhanced antidiabetic properties relative to an MF water extract. A HPLC pattern analysis revealed that LLE is necessary to observe changes in the levels of compounds in an enzyme-processed MF extract because it reduces matrix effects. Five compounds were selected as marker compound candidates (syringaldehyde, transcaffeic acid, morin 3-O- $\beta$-D-glucopyranoside, astragalin, and moracin $M \quad 3^{\prime}$-O- $\beta$-glucopyranoside) for quality control of the bioconverted MF extract because they showed antidiabetic functions. A HPLC method was developed using the five candidate compounds, and they were analyzed within $60 \mathrm{~min}$. The new method was well validated, and sample preparation was optimized by RSM. Among the five marker compounds, the concentration of two compounds (syringaldehyde and transcaffeic acid) known to have antidiabetic properties were increased in the bioconverted MF extract processed by
Viscozyme. The new HPLC method and the marker compounds will enable the development of antidiabetic functional foods, and quality control of commercial MF extracts obtained by bioconversion using enzymes (e.g., Viscozyme).

\section{Supplementary Information}

The online version contains supplementary material available at https://doi. org/10.1186/s40543-020-00253-3.

Additional file 1: Supplementary Figure 1. HPLC chromatograms of (a) water extract and (b) bio-converted MF extract without LLE. Supplementary Figure 2. Effect of acidic modifier on HPLC chromatograms of MF at $320 \mathrm{~nm}$; (a) non acidic modifier in modifier and (b) $0.1 \%$ formic acid in mobile phase. Supplementary Figure 3. Change of HPLC chromatograms of MF at $320 \mathrm{~nm}$ by controlling gradient conditions; $\mathrm{M0}$ : B\% 5-20-100 (115 min), M1: B\% 10-20-61 (70 min), M2: B\% 15-20-45 (70 min) and M3: B\% 15-20-45 (60 min). Supplementary Figure 4. Effect of solvent on MF extraction at $320 \mathrm{~nm}$; (a) 100\% methanol, (b) 50\% methanol and (c) water. Supplementary Figure 5. Specificity of five major peaks in sample by comparing three points of UV spectrums at same peak: (a), (b), (c), (d) and (e). Supplementary Table 1. Optimization of sample preparation by RSM. Supplementary Table 2. Comparison of predicted and experimental values based on peak area $(n=6)$. Supplementary Table 3. Linearity, LOQs and LODs of the analytes. Supplementary Table 4. Intra-day and inter-day accuracy and precision of major compounds $(n=5)$. Supplementary Table $\mathbf{5}$. Repeatability of major compounds $(n=6)$. Supplementary Table 6 . Recovery of the developed method $(n=6)$.

\section{Abbreviations}

MF: Mori Folium; LLE: Liquid-liquid extraction; HPLC: High-performance liquid chromatography; RSM: Response surface methodology; LC-MS: Liquid chromatography-mass spectrometry; GR: Guaranteed reagent; DAD: Diode array detection; ESI: Electrospray ionization; LOD: Limits of detection; LOQ: Limits of quantification; S/N: Signal-to-noise; CCD: Central composite design; UV: Ultraviolet

\section{Acknowledgements}

The authors thank the Institute of Drug Research and Development in College of Pharmacy, CNU, for supporting students.

\section{Authors' contributions}

Conceptualization: JS Kang, KT Kim. Writing: TJ Kim, JH Kim. Review: JS Kang, KT Kim, JH Kim. Analysis: TJ Kim, HJ Kim, JW Cho, JH Kim. Additional works: JH Kim. All authors agreed position and publication.

\section{Funding}

This work was supported by Korea Institute of Planning and Evaluation for Technology in Food, Agriculture, Forestry, and Fisheries through AgriBioindustry Technology Development Program, funded by the Ministry of Agriculture, Food, and Rural Affairs (MAFRA) (No. 315024-3). 


\section{Availability of data and materials}

The datasets of this manuscript are available upon request.

\section{Competing interests}

The authors declare no conflict of interest.

\section{Author details}

'College of Pharmacy, Chungnam National University, Daejeon 34134, South Korea. ${ }^{2}$ MSC Annexed Food Technology Research Institute, Yangsan 50518, South Korea. ${ }^{3}$ Department of Food Science and Technology, Dong-Eui University, Busan 47340, Korea.

Received: 22 June 2020 Accepted: 2 December 2020

Published online: 05 January 2021

\section{References}

Anson N, Selinheimo E, Havenaar R, Aura AM, Mattila I, Lehtinen P, Bast A, Poutanen K, Haenen G. Bioprocessing of wheat bran improves in vitro bioaccessibility and colonic metabolism of phenolic compounds. J Agric Food Chem. 2009;57:6418-25.

Chang YC, Yang MY, Chen SC, Wang CJ. Mulberry leaf polyphenol extract improves obesity by inducing adipocyte apoptosis and inhibiting preadipocyte differentiation and hepatic lipogenesis. J Funct Foods. 2016;21: $249-62$.

Chen N, Zeng Q, Lin Q, Rao J. Development of defatted soy flour based bioadhesives using viscozyme L. Ind Crop Prod. 2015:76:198-203.

Cho BO, Che DN, Yin HH, Jang SI. Gamma irradiation enhances biological activities of mulberry leaf extract. Radiat Phys Chem. 2017:133:21-7.

Choi J, Kang HJ, Kim SZ, Kwon TO, Jeong SI, Jang SI. Antioxidant effect of astragalin isolated from the leaves of Morus alba $\mathrm{L}$. against free radicalinduced oxidative hemolysis of human red blood cells. Arch Pharm Res. 2013;36(7):912-7

Dhungyal B, Koirala P, Sharma C, Jha DK. Caffeic acid - a potent phytocompound against diabetes mellitus. SMU Med J. 2014;1(2):152-61.

Eo HJ, Park JH, Park GH, Lee MH, Lee JR, Koo JS, Jeong JB. Anti-inflammatory and anti-cancer activity of mulberry (Morus alba L.) root bark. BMC Complement Altern Med. 2014:14(200):1-9.

Guan X, Yao H. Optimization of viscozyme L-assisted extraction of oat bran protein using response surface methodology. Food Chem. 2008;106(1):34551.

He X, Fang J, Ruan Y, Wang X, Sun Y, Wu N, Zhao Z, Chang Y, Ning N, Guo H, Huang L. Structures, bioactivities and future prospective of polysaccharides from Morus alba (white mulberry): a review. Food Chem. 2018;245:899-910.

Huang $\mathrm{CH}$, Chen MF, Chung HH, Cheng JT. Antihyperglycemic effect of syringaldehyde in streptozotocin-induced diabetic rats. J Nat Prod. 2012; 75(8):1465-8.

Huang SS, Yan YH, Ko CH, Chen KM, Lee SC, Liu CT. A comparison of food-grade folium mori extract and 1-deoxynojirimycin for glycemic control and renal function in streptozotocin-induced diabetic rats. J Tradit Complement Med. 2014:4(3):162-70.

Jha OY, Cao X, Yuan W, Zhang WWQ, Zhao M, Duan JA. Pharmacokinetic study of rutin and quercetin in rats after oral administration of total flavones of mulberry leaf extract. Braz J Pharmacogn. 2013;23(5):776-82.

Jin H, Lee WS, Eun SY, Jung JH, Park HS, Kim G, Choi YH, Ryu CH, Jung JM, Hong SC, Shin SC, Kim HJ. Morin, a flavonoid from Moraceae, suppresses growth and invasion of the highly metastatic breast cancer cell line MDA-MB231 partly through suppression of the Akt pathway. Int J Oncol. 2014;45(4):162937.

Jung SH, Han JH, Park HS, Lee DH, Kim SJ, Cho HS, Kang JS, Myung CS. Effects of unaltered and bioconverted mulberry leaf extracts on cellular glucose uptake and antidiabetic action in animals. BMC Complement Altern Med. 2019; 19(55):12

Kang KB, Kim SD, Kim TB, Jeong EJ, Kim YC, Sung JH, Sung SH. Tyrosinase inhibitory constituents of Morus bombycis cortex. Nat Prod Sci. 2011;73(3): 198-201.

Kim GN, Jang HD. Effect of enzyme treatment with $\beta$-glucosidase on antioxidant capacity of mulberry (Morus alba L.) leaf extract. Food Sci Biotechnol. 2010; 19(5):1341-6.

Le VNH, Lee WJ, Kim YH, Chae GH, Chin YW, Kim KT, Kang JS. High-performance liquid chromatography method development for the quality control of Ginkgonis semen. Arab J Chem. 2017;10(6):792-800.
Liu LK, Chou FP, Chen YC, Chyau CC, Ho HH, Wang CJ. Effects of mulberry (Morus alba L.) extracts on lipid homeostasis in vitro and in vivo. J Agric Food Chem. 2009:57(16):7605-11.

Oku T, Yamada M, Nakamura M, Sadamori N, Nakamura S. Inhibitory effects of extractives from leaves of Morus alba on human and rat small intestinal disaccharidase activity. Br J Nutr. 2006;95(5):933-8.

Pothinuch P, Miyamoto A, Nguyen HTT, Tongchitpakdee S. Vasodilatory effects of mulberry (Morus spp.) leaf extract on porcine cerebral arteries in vitro: possible underlying mechanisms. J Funct Foods. 2017;38:151-9.

Seo KH, Lee DY, Jeong RH, Lee DS, Kim YE, Hong EK, Kim YC, Baek NI. Neuroprotective effect of prenylated arylbenzofuran and flavonoids from Morus alba fruits on glutamate-induced oxidative injury in HT22 hippocampal cells. J Med Food. 2015;18(4):403-8.

Sohn HY, Son KH, Kwon CS, Kwon GS, Kang SS. Antimicrobial and cytotoxic activity of 18 prenylated flavonoids isolated from medicinal plants: Morus alba L., Morus mongolica Schneider, Broussnetia papyrifera (L.) Vent, Sophora flavescens Ait and Echinosophora koreensis Nakai. Phytomedicine. 2004;11(7-8): 666-72.

Tallini LR, Pedrazza GPR, Bordignon SAL, Costa ACO, Steppe M, Fuentefria A, Zuanazzi JAS. Analysis of flavonoids in Rubus erythrocladus and Morus nigra leaves extracts by liquid chromatography and capillary electrophoresis. Braz J Pharmacogn. 2015;25(3):219-27.

Thirugnanasambandham K, Sivakumar V, Maran JP. Microwave-assisted extraction of polysaccharides from mulberry leaves. Int J Biol Macromol. 2015;72:1-5.

Tyszka CM, Konieczny P, Majka M. Caffeic acid expands anti-tumor effect of metformin in human metastatic cervical carcinoma HTB-34 cells: implications of AMPK activation and impairment of fatty acids de novo biosynthesis. Int J Mol Sci. 2017;18(2):1-16.

Ustundag AO, Ozdogan M. Usage possibilities of mulberry leaves in poultry nutrition. Sci Pap Ser D Anim Sci. 2015;58:170-8.

Vendrig JC, Buffel K. Growth-stimulating activity of trans-caffeic acid isolated from Coleus rhenaltianus. Nature. 1961;192(4799):276-7.

Vichasilp C, Nakagawa K, Sookwong P, Suzuki Y, Kimura F, Higuchi O, Miyazawa T. Optimization of 1-deoxynojirimycin extraction from mulberry leaves by using response surface methodology. Biosci Biotechnol Biochem. 2009;73(12):26849

Yang JH, Han JS. Effect of mulberry leaf extract supplement on blood glucose, glycated hemoglobin and serum lipids in type II diabetic patients. J Korean Soc Food Sci Nutr. 2006;35(5):549-56.

Yang N, Zhang N, Jin Y, Jin Z, Xu X. Development of a fluidic system for efficient extraction of mulberry leaves polysaccharide using induced electric fields. Sep Purif Technol. 2017;172:318-25.

Ying Z, Han X, Li J. Ultrasound-assisted extraction of polysaccharides from mulberry leaves. Food Chem. 2011;127(3):1273-9.

Zhang W, Han F, HE J, Duan C. HPLC-DAD-ESI-MS/MS analysis and antioxidant activities of nonanthocyanin phenolics in mulberry (Morus alba L.). J Food Sci. 2008;73:512-8.

Zhang Y, Ren C, Lu G, Cui W, Mu Z, Gao H, Wang Y. Purification, characterization and anti-diabetic activity of a polysaccharide from mulberry leaf. Regul Toxicol Pharmacol. 2014;70(3):687-95.

\section{Publisher's Note}

Springer Nature remains neutral with regard to jurisdictional claims in published maps and institutional affiliations. 